\title{
Assessment improvement of road accidents on highways of the Far North as the basis for sustainable regional development
}

\author{
Dmitry A. Skorobogatchenko ${ }^{1}{ }^{*}$ Vitaly S. Borovik ${ }^{2}$, Vitaly V. Borovik ${ }^{3}$, Anton Y. Zhabunin ${ }^{4}$, Roman R. Chugumbaev \\ ${ }^{1}$ Volgograd State Technical University, \\ ${ }^{2}$ Volgograd Scientific and Technological Center, \\ ${ }^{3}$ State Owned Public Enterprise of Volgograd region «Directorate of highways», \\ ${ }^{4}$ Volzhsky Polytechnic Institute, \\ ${ }^{5}$ Russian Transport University,
}

\begin{abstract}
The paper substantiates the need to assess the road safety in the specific conditions of the Far North by means of the analysis of the factors in the "driver-car-road-environment" system. The authors suggest a methodology for assessment of road traffic accidents, which makes it possible to take into account a wide range of factors affecting road accidents. In particular, the simulation takes into account the characteristics of the driver, technical condition of the vehicle, road conditions, weather and climate. Adaptive neural networks based on fuzzy inference systems are used as a tool for road safety assessment. The authors mention the results of statistical studies on a number of variables of the "driver-car-road-environment" system, which make it possible to form membership functions in the fuzzy inference system. The final part of the paper presents the practical results of road safety assessment for various categories of drivers in different road conditions in one of the largest cities in the Far North.
\end{abstract}

\section{Introduction}

The Far North has as natural reserves up to $90 \%$ of coal deposits, significant oil and gas reserves, almost the entire volume of explored rare earth metals and diamonds, half of the iron ore deposits, $80 \%$ of forest resources and more than $60 \%$ of fresh water reserves of the Russian Federation [1]. At the same time, at present, the transport system of the region is characterized by extremely uneven development and a poor use. The lag in transport infrastructure development results in an increase in the cost of transportation of goods and passengers. Thus, the share of transportation costs in the value of the final product of the Far North and the Arctic zone is up to $60 \%$. The dependence of the regions mentioned above on supplies is more than $90 \%$, and the cost of road transport in the Far North is 5-10 times higher than in the central part of the Russian Federation and 1.5 times higher than that in similar areas of other countries of the world [2].

Thus, the key condition for the implementation of Russia's strategic plans to involve huge natural raw materials and other economic resources in the economic turnover is the effective functioning of the road transport system of the Far North and the Arctic zone. A significant problem affecting the efficiency of the road transport complex in the regions of the Far North is the road accident rate, which has serious demographic, economic and social consequences. Despite the fact that the number of road accidents on highways of the Far North is insignificant due to the low population density and, as a consequence, insignificant motorization, in cities the percentage of road accidents remains quite high (Figure 1). More than a quarter of people killed on the roads are the most active people of the working age, and the situation makes a serious demographic problem.

In addition to direct losses associated with death and injury of people, when assessing the socio-economic damage from road accidents, the damage to the owners of motor vehicles, loss of road maintenance services, loss of cargo owners, police costs and medical institutions, costs of enterprises and institutions whose employees became participants in road accidents, costs of social security agencies, as well as a number of additional indirect costs are calculated independently.

One of the mesures reducing the number of accidents and the severity of their consequences is the development of organizational steps in the field of traffic safety, as well as automated systems for assessment and accident prevention, which have significant features in the Far North. 


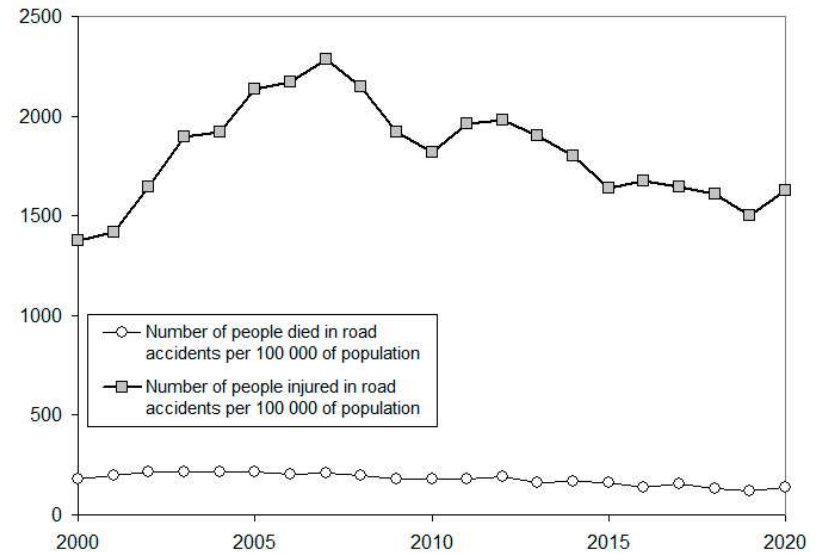

Figure 1. Analysis of the accident rate in the Far North in dynamics, 2000-2020.

The accident rate in the North is determined significantly by the actual condition of pavement, characteristics of speed regime, time and seasonality. Consequently, the definition of traffic safety in the Far North must be carried out taking into account road conditions [3]. It should be noted that the accident rate in the North significantly depends on the behavior of the driver and the technical condition of the car, as well as the transport and operational state of the road, peculiarities of natural and climatic impact on both road conditions and the operation of the car and, in particular, on the behavior of drivers and pedestrians [4]. At the same time, if the number of accidents caused by technical problems of vehicles and unsatisfactory transport and operational state of road decreases every year, then the number of accidents connected with the violation of traffic rules by drivers is steadily increasing.

Consequently, at present, the following issues connected with the assessment of road accidents in a complex socio-economic system are of particular relevance and they are presented as objective factors which are becoming urgent: design parameters and road condition, traffic intensity of vehicles and pedestrians, road construction with facilities and means of regulation, time of year, hours of the day. The subjective factors, characterizing the features and condition of drivers and pedestrians, as well as their violation of established rules are also taken in consideration.

The aim of the study is to develop an automated system for a comprehensive assessment of road safety in the framework of the "driver-car-road-environment" system.

\section{Analysis of methodological approaches to problem solution}

Since the assessment of road safety in the "drivercar-road-environment" system aims to take into account the maximum possible number of parameters for each of the factors that form the system as a whole, the most common integrated approaches are presented in the following paper [5]. As an example of the implementation of automated safety assessment systems based on a comprehensive assessment of "driver-car- road-environment", we can mention the following study [6], which presents a family of computer simulation models, many of which formed the basis of official documents introduced into practice. A specificity of this direction is the ability to obtain the quantitative assessment of the totality of factors that have the greatest impact on road traffic situation within a particular road segment.

The weakest link in the "driver-car-roadenvironment" system is the person. In this regard, a significant part of the approaches to automated safety assessment is based on considering "driver-car-roadenvironment" system as a biotechnical system with the identification of psychophysiological characteristics of drivers [7].

There are a number of papers that, although they analyse traffic safety in the framework of "driver-carroad-environment" system, they focus on the reliability of individual parameters of the system. So in the following paper [8], a complex of simulation models for accident rate assessment based on road parameters, road condition and the quality of drivers is described. There are a number of studies assessing the reliability of vehicle mechanisms and the reaction of drivers when assessing road accidents [9].

Both the classical approaches of the probability theory mathematical statistics and modern Big Data technologies are used as tools for the use of automated traffic safety assessment within the "driver-car-roadenvironment" [10]. The method of hierarchy analysis and expert assessments are widely used in the design of "driver-car-road-environment" assessment systems [11].

\section{Safety assessment model in the Far North}

The general structure of the "driver-car-roadenvironment" system in terms of road safety assessment is described in sufficient detail in a variety of scientific studies. It is substantiated that the assessment of the accident rate in the "driver-car-road-environment" system is well formalized using the method of expert assessments. However, the use of this technique is difficult, due to a large volume of input data, and it is difficult to isolate within them patterns that simplify the construction of the rule base. Therefore, as an implementation tool, a set of instruments of fuzzy neural networks of the ANFIS type was chosen, which, through training, automatically generate a rule base. The details of the functioning and principles of the network are presented in the paper [12].

Let us analyze the features of the variables that form the basis for the formation of term sets of variables for the conditions of the Far North.

All researchers agree that changes in a driver's performance are influenced by age, which affects the mental and emotional state of the driver [13]. At the same time, among young and middle-aged drivers, the risk of road accidents for men is significantly higher than for women, while among older drivers the opposite tendency prevails, i.e. the risk of road accidents for older 
women is higher than for men of the same age. The study of individual characteristics of driver behavior is shown in Figure 2.

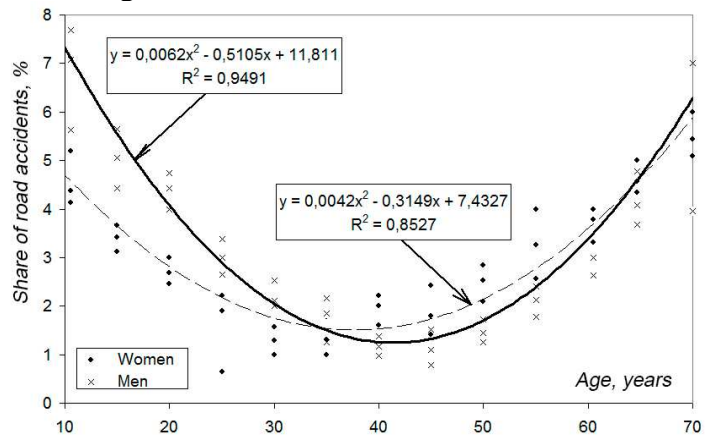

Figure 2. Analysis of accidents in dependence on age and gender of the driver.

The safety of the factor "car" in the Far North is largely influenced by weather and road conditions. In general, when describing the reliability of this factor, the efficiency of the vehicle safety systems was taken into account, with respect to time between failures in time. The results of observations of vehicle failures are shown in Figure 3.

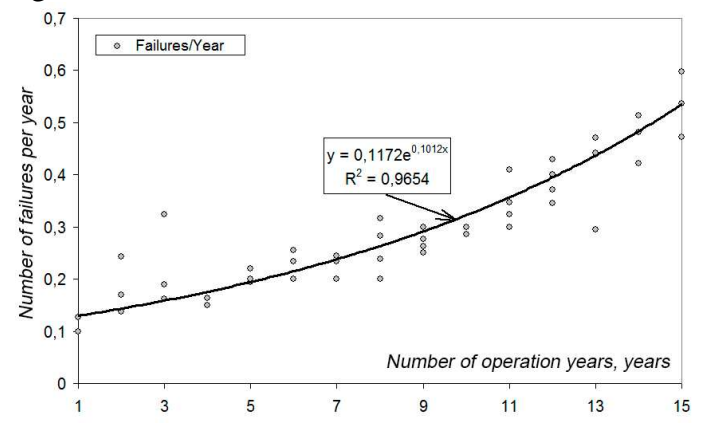

Figure 3. Reliability analysis for «car» factor.

When assessing the "road" factor, it is advisable to use a system of variables defined by the concept of "road conditions". In this case, the most significant variables that determine traffic safety in the "driver-car-roadenvironment" system are the intensity of traffic flow and the vehicle speed (Figure 4).

The environment or meteorological conditions are the main external factors affecting all other elements of the "driver-car-road-environment" system. Weather and climate in the Far North have a significant impact on the general psychophysical state of both the driver and the pedestrian.

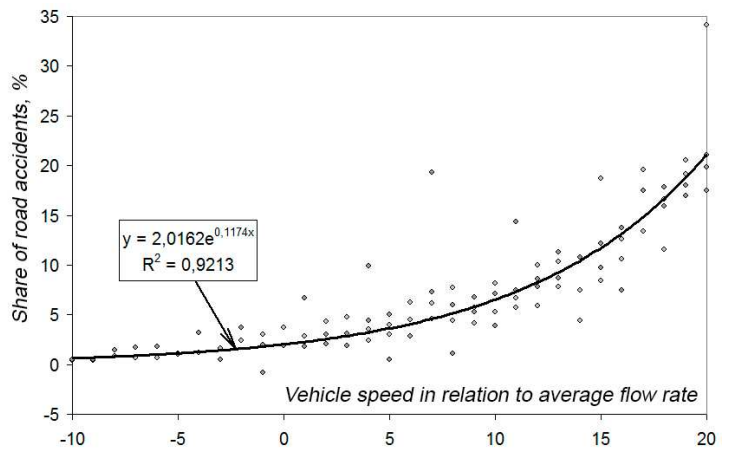

Figure 4. Analysis of incidence of road accidents depending on the change in vehicle speed in relation to average flow rate
There are a lot of scientific studies devoted to the analysis of changes in the consumer qualities of roads and road structures under the influence of weather and climate. And if the influence of pavement condition on road safety is well studied, then the effect of temperature and pressure changes on the driver's behavior had to be developed by forming the "driver-car-road-environment" system of variables (Figure 5).

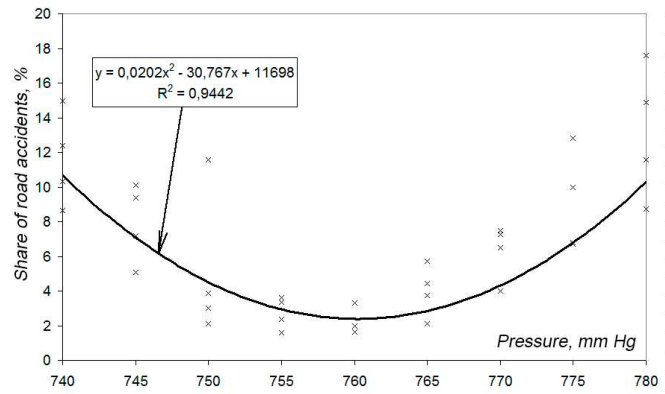

Figure 5. Influence of atmospheric pressure on accidents caused by the driver.

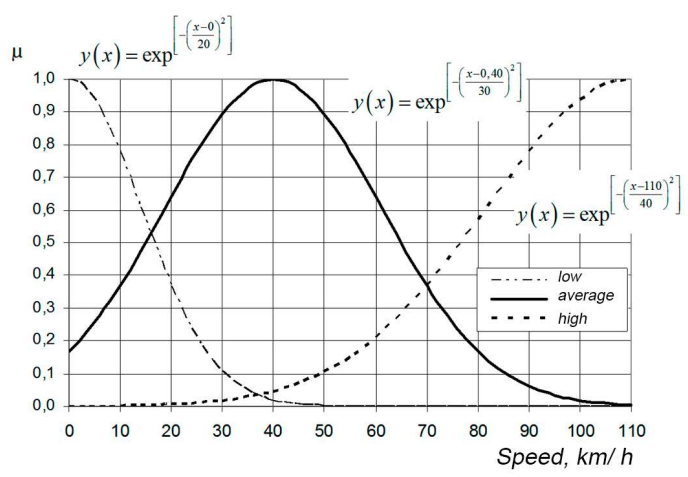

Figure 6. Membership functions used as the example of the variable "speed"

Taking into account the dependencies of the type presented in Figures 2-5 and similar ones, not presented in the paper by the authors for reasons of article volume growth, for all variable factors "driver", "car", "road", term sets for linguistic variables are identified. As an example of the formation of term sets before normalization, Figure 6 presents data on the variable "vehicle speed". The general structure of the input variables is shown in Figure 7.

On the basis of the formed term sets, an artificial NNN was developed, which is a parallel computing system consisting of a large number of elementary information processing units i.e. neurons that accumulate experimental knowledge and provide them for further processing (see Figure 7). 


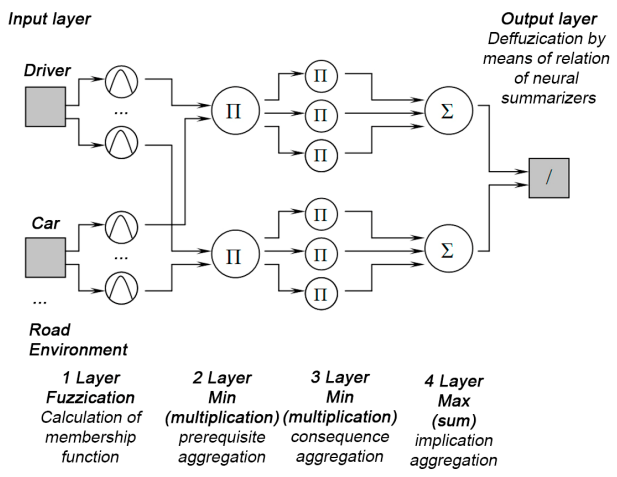

Figure 7. General diagram of the NNN structure, according to the assessment of traffic accidents on highways

The general structure of input layer variables is shown in Figure 8.

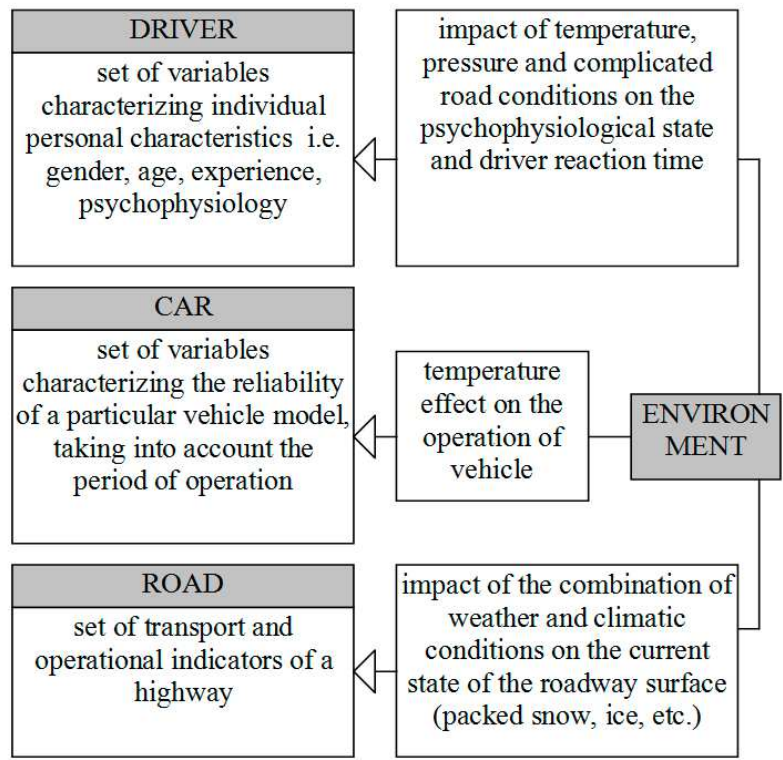

Figure 8. The set of input variables in the NNS, according to the assessment of traffic accidents on highways

Fuzzification is carried out on the first layer of the $\mathrm{NNN}$, according to the assessment of road traffic accidents.

$$
\mu_{A}^{(k)}\left(x_{i}\right)=\frac{1}{1+\left(\frac{x_{i}-c_{j}^{(k)}}{\sigma_{j}^{(k)}}\right)^{2 b_{j}^{(k)}}}
$$

where $k$ - number of membership functions $(k=1 \ldots M) ; x_{i}$ - current value of the $i$-th input variable after normalization; $j-$ number of variables $(j=1 \ldots N) ; \quad c_{j}^{(k)}, \sigma_{j}^{(k)}, b_{j}^{(k)}$ - parameters that determine, respectively, the center, width and shape of the $k$-th membership function of the $j$-th variable.

In the second layer, the values of variables $x_{i}$ are aggregated in accordance with the formula:

$$
w_{k}=\prod_{j=1}^{N} \frac{1}{1+\left(\frac{x_{i}-c_{j}^{(k)}}{\sigma_{j}^{(k)}}\right)^{2 b_{j}^{(k)}}}
$$

The parameters $w_{k} \quad(k=1 \quad \ldots l \mathrm{M})$ calculated in this way are simultaneously sent further into the 3rd layer (for the multiplication by weights) and into the fourth layer for the calculation of their sum in the neuron $f_{2}$.

The third layer calculates the centers for $k$-rules using the formula:

$$
y_{k}=p_{k 0}
$$

where $p_{k 0}$ can be viewed as the center of the membership function $c k$.

After that the aggregation of consequence is made by means of the algebraic multiple carried out: $w_{k} \times y_{k}(\mathbf{x})$.

The fourth layer is presented by two neurons: $f_{1}$ and $f_{2}$ performing the aggregation of results:

$$
\begin{gathered}
f_{1}=\sum_{k=1}^{M} w_{k} \times y_{k}(\mathbf{x})=\sum_{k=1}^{M}\left[\left(\prod_{j=1}^{N} \mu_{A}^{(k)}\left(x_{j}\right)\right) \times c_{k}\right] \\
f_{2}=\sum_{k=1}^{M} w_{k}=\sum_{k=1}^{M}\left[\prod_{j=1}^{N} \mu_{A}^{(k)}\left(x_{j}\right)\right]
\end{gathered}
$$

The fifth layer is presented by a single neuron performing defuzzification:

$$
\begin{gathered}
y(x)=\frac{f_{1}}{f_{2}}=\frac{\sum_{k=1}^{M} w_{k} \times y_{k}(\mathbf{x})}{\sum_{k=1}^{M} w_{k}}= \\
=\frac{\sum_{k=1}^{M}\left[\left(\prod_{j=1}^{N} \mu_{A}^{(k)}\left(x_{j}\right)\right) \times c_{k}\right]}{\sum_{k=1}^{M}\left[\prod_{j=1}^{N} \mu_{A}^{(k)}\left(x_{j}\right)\right]}
\end{gathered}
$$

The NNN learning algorithm can be conditionally divided into two stages. Initially, the parameters of the center of the output membership functions in the third layer are subject to training. Further, using the gradient descent method, the parameters of the membership functions of the first layer are adjusted.

\section{Conclusions and discussion}

Analyzing the presented dependencies, it is obvious that the accident rate changes during the week having the peaks in the morning and on Saturday. Also, the diagrams clearly show the difference in accident rates for men and women of different ages. Particularly 
noteworthy one is the tendency of an increase in the accident rate among drivers with significant experience, caused by traffic conditions (nighttime and negative temperatures).

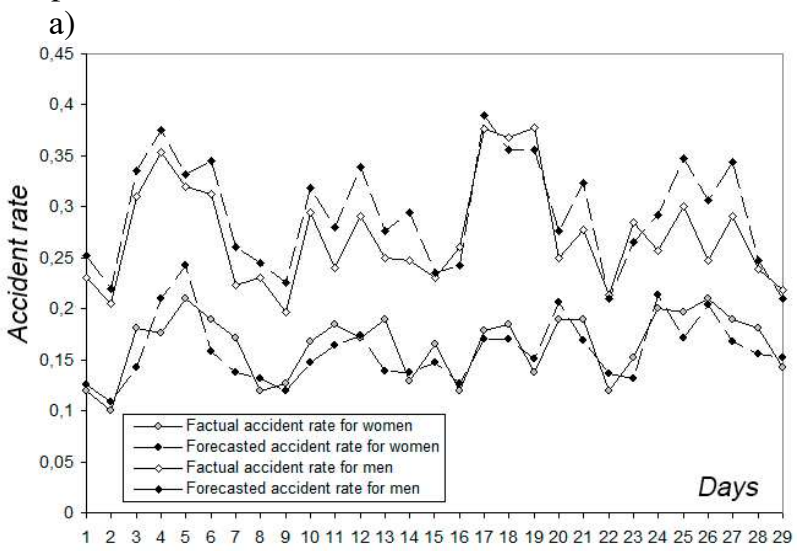

b)

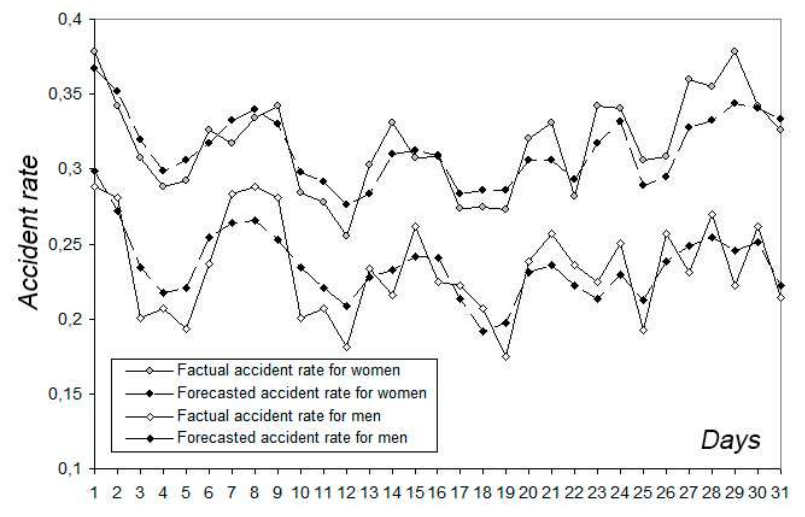

Figure 9. Forecast of the accident rate on the roads of Murmansk: a) for drivers under 25 in the daytime, June; b) for drivers 35-50 years old, in the nighttime, February.

In general, it can be concluded that the authors have developed a model for accident rate assessment taking into account the individual characteristics of the driver, traffic conditions and the specifics of the impact of weather and climate. As a result of training the NNS underlying the model, sufficiently accurate results of the accident rate assessment were obtained (error is less than $10 \%$ ). The model makes it possible to take into account the peculiarities of the regions of the Far North and, in particular, the influence of road conditions, weather and climate on the behavior of drivers and the operation of vehicles when assessing the accident rate. The practical use of the dependencies suggested by the authors will make it possible to develop measures to reduce the accident rate on the roads of the Far North, and, therefore, to increase the efficiency of the road transport complex, which will directly contribute to the social and economic development of the region.

\section{References}

1. I.V. Samsonova, A.B. Yarlykapov Economic policy, 4, 13-18 (2016)
2. A.V.Shpak, V.A. Serova National interests: priorities and security, 17, 31-36 (2011)

3. J.J. Rolison, S. Regev, S. Moutari, A. Feeney Accident Analysis \& Prevention, 115, 11-24 (2018)

4. Haque M. Ohidul, Haque Tariq H. Transportation Research Part A: Policy and Practice, 118, 594-607 (2018)

5. V.A. Korchagin, S.A. Lyapin, V.E. Klyavin, V.V.Sitnikov Fundamental research, 6-2, 251-256 (2015)

6. V.M. Eremin CAD and GIS systems of automobile roads, 1(2), 90-93 (2014)

7. A. Bennajeh, S. Bechikh, L.B. Said, S. Aknine Transactions on Computational Collective Intelligence XXX. Lecture Notes in Computer Science, 11120 (2018)

8. A.V. Skrypnikov, E.V. Kondrashova, S.V. Dorokhin, A.G. Chistyakov Bulletin of Voronezh State University of Engineering Systems, 3(61), 7783 (2014)

9. S.N. Lazarev, N.A. Oreshyn, D.A. Mamleev Management of road safety activities: state, issues, ways of improvement, 1(2), 278-284 (2019)

10. H. Wang, XY. He, LY. Chen, et al. J. Comput. Sci. Technol, 35, 875-888 (2020)

11. E.S. Voevodin, E.V. Fomin, K.V. Pulyanova, A.M. Askhabov, A.S. Kashura, N.V. Golub Bulletin of Irkutsk State Technical University, 5(136), 240-250 (2018)

12. D.A. Skorobogatchenko Bulletin of Volgograd State University of Architecture and Civil Engineering. Series: Construction and Architecture, 45(64), 188198, (2016)

13. S. Ghaemi, S. Khanmohammadi, M.A. Tinati, International Journal of Control, Automation and Systems, 10, 517-528 (2012)

14. D.A. Skorobogatchenko, A.V. Erohin Bulletin of Volgograd State University of Architecture and Civil Engineering. Series: Construction and Architecture, 36(55), 174-181 (2014) 